\title{
Adaptive frameworks of chronic pain: daily remakings of pain and care at a Somali refugee women's health centre
}

\author{
Kari Campeau
}

\section{Correspondence to Kari Campeau, Department of Writing Studies, University of Minnesota, Minneapolis, MN 55455, Minnesota, USA; campeau@umn.edu}

Accepted 20 April 2018 Published Online First 19 May 2018
Check for updates

To cite: Campeau K Med Humanit

2018:44:96-105.

\begin{abstract}
Pain is an intensely subjective experience and one that is difficult for healthcare professionals to treat. Chronic pain, often diffuse, cyclical and involving many systems of the body, is often not well treated in a medical system that relies on discrete symptoms, identifiable causes, external pathogens and physician specialisation. Pain has its own problems specific to Somali diaspora populations, where chronic pain is prevalent but often undertreated, and where Somali patients face barriers of access to medicine. This study, conducted in partnership with a Somali women's health centre, seeks to understand Somali women's use of informal and formal networks of healthcare. Drawing from qualitative interviews with Somali, refugee women, this article identifies four emerging frameworks through which participants experience chronic pain: (1) pain as a symptom of exile; (2) pain and the strength to bear pain as issues of faith; (3) medicine as powerful, curative and fluid; (4) medical discrimination and exclusion.
\end{abstract}

\section{INTRODUCTION}

Glass shards in my chest. A slow fire. Getting stung by a bee, over and over again. My bones emptying out. Sand behind my eyes.

Participants in this study, Somali women living with chronic pain, often try to fit pain to words, as do many people seeking aid for chronic pain. Chronic pain, often experienced as diffuse and cyclical pain and fatigue, is difficult to treat in the American medical system, one that relies on discrete symptoms, identifiable causes, external pathogens and physician specialisation. As a result, pain is undertreated in the USA. ${ }^{1-3}$ Chronic pain provokes questions about cultural and medical constructions of illness, distinctions between expert and lay knowledges and the differences between disease as a medical object and illness as a subjective experience. As growing numbers of diverse Americans live with chronic pain, the need to describe and translate pain across differences in culture, expertise and experience is becoming more consequential and complex. $^{1-3}$

\section{Pain definitions}

This study uses the International Association of the Study of Pain's (IASP) definition of pain. ${ }^{4}$ The IASP defines pain as 'an unpleasant sensory and emotional experience associated with actual or potential tissue damage, or described in terms of such damage'. The definition specifies that the reality of pain relies neither on an individual's ability to communicate pain nor on a professional's recognition of pain: 'the inability to communicate verbally does not negate the possibility that an individual is experiencing pain and is in need of appropriate pain-relieving treatment. Pain is always subjective'. This definition recognises that chronic pain may occur without physical, external stimuli, and that all reported pain is 'real'.

The IASP's definition of pain, while accessible and flexible, derives from a Western approach to the body; because pain expression is shaped by social and cultural factors, ${ }^{5}$ it is important to account for Somali understandings of pain. There are no studies, to my knowledge, that address how pain is understood and treated in Somalia by Somalis, yet several qualitative and clinical studies of Somali refugees' experiences of pain offer insight into Somali ways of knowing, expressing and treating pain. ${ }^{6-8}$ In Tiilikainen's study of Somali women in Finland, Somali women explained that in Somalia pain symptoms were caused by jinns or evil spirits, but all of the women interviewed claimed to no longer believe in jinns. ${ }^{6}$ Tiilikainen traces a history of relating bodily ills to divine causation and an understanding of bodies as contiguous with their environments. The study of Somali women in Finland by Finnström and Söderhamn found that some Somali women identified pain as a purely physical experience while others interpreted pain as 'something deeper', imbricated in emotional and bodily experiences. ${ }^{7}$ These fluctuating definitions of pain make sense considering the Somali word xanuun means both pain and illness. ${ }^{8}$ Pain is an elastic term that can describe many embodied and uncomfortable experiences. Finnström and Söderhamn found that Somali women express pain through resting, confiding in friends and family members or reading religious texts. ${ }^{8}$ These studies show that Somalis often relate to pain as a broad, interpersonal and multicausal bodily experience.

\section{Disparities in pain treatment in the USA}

While pain is chronically undertreated for all people in the USA, race, gender and ethnicity can determine how quickly, accurately and under what circumstances patients are likely to have their pain diagnosed and treated. ${ }^{1-39-24}$ 


\section{Gender and pain}

Women are more likely to experience chronic pain than men. ${ }^{910}$ Women are also more likely to have their symptoms attributed to psychosomatic causes, like neuroticism, hypochondria, stress or emotional distress. ${ }^{2}$ 10-13 Multiple studies have found that women are more likely to be given sedatives for pain, whereas men more often are prescribed pain medication. ${ }^{11-15}$ These findings show that women's pain is more likely to be treated as emotional, while men's pain is more likely to be treated as physical. Fillingim et al literature review on gender and pain provides further evidence of gender bias in pain treatment. ${ }^{11}$ For example, in the emergency department, women reporting acute abdominal pain ${ }^{12}$ and cardiac pain ${ }^{13}$ were less likely than men to receive analgesics for their pain, ${ }^{12} 13$ even after physicians were made aware of these gender disparities in pain treatment. ${ }^{13}$ In their review of gender bias in pain medication prescription, Hoffmann and Tarzian conclude that when it comes to pain reporting, the burden of proof rests uniquely on women; women are treated less aggressively for pain in initial encounters with healthcare providers until they 'prove that they are as sick as male patients' (p. 17) ${ }^{14}$; for other examples, see Calderone, ${ }^{15}$ Tsang et al, ${ }^{16}$ Nayak et al $^{17}$ and Lichtman et al. ${ }^{18}$

\section{Race and pain}

In their review on pain, race and ethnicity, Edwards et al observe that while more researchers address effects of race and ethnicity on pain treatment, there remains no consensus on operational definitions of these terms. ${ }^{19}$ Heeding this critique, this study defines race as a category that 'distinguishes major groups of people according to their ancestry and a more or less distinctive combination of physical characteristics' (p. 134). ${ }^{19}$ Ethnicity 'focuses on the distinction between groups of people based on behaviour and culture as well as biology and physical characteristics' (p. 134). ${ }^{19}$ This study uses race and ethnicity as categories useful to study social, political and cultural dimensions of pain experience.

Studies have shown that African-American patients are undertreated for pain. ${ }^{20-27}$ Studies show that black patients are less likely than white patients to receive pain medication ${ }^{20-22}$ and, when black patients are given pain medications, they receive less than their white counterparts. ${ }^{23}$ This evidence likely points to an overprescription of pain medication for white patients, ${ }^{23}$ yet this implication does not invalidate conclusions that pain claimed by black patients is often underestimated. Indeed, belief that black people experience pain in ways fundamentally different from white people stretches back to American slavery. Beliefs that black and white people are biologically different were promulgated by slave owners, scientists and doctors. ${ }^{24} 25$ Into the 20th century, physicians were taught that black bodies could handle surgical operations with little or no pain and thus rarely administered anaesthesia. ${ }^{24}$ By the mid-20th century, clinical studies often excluded people of colour and women and regarded a white, male body as the medical standard, ${ }^{24}$ yet, researchers continued to conduct unethical medical experiments on African-Americans based in part on the belief that black bodies were less susceptible to pain. ${ }^{24}$ Most famously, the US Public Health Service and the Tuskegee Institute conducted a 40-year study (1932-1971) of the progression of untreated syphilis in black men who did not know they had syphilis. ${ }^{25}$

Recent studies show that some medical professionals and laypeople continue to believe that race is a biological category that determines pain vulnerability. ${ }^{26} 27$ Trawalter et al interviewed 222 white medical students and found that at least half of participants harboured false beliefs about race and biology, and that those who held false beliefs also 'rate[d] the physical pain of a hypothetical black patient as less severe than that of a white patient in the same circumstances'. ${ }^{27}$ This study suggests that racial disparities in pain management do not primarily result from physicians recognising and deciding not to treat pain in black patients, but that disparities are more likely the result of physicians not recognising pain reported by black patients. Although researchers have offered multiple explanations for racial disparities in pain treatment, including assumptions about patients' inability to pay for treatments ${ }^{27}$ and racial prejudice, ${ }^{2}$ this study concludes that racial disparity 'is likely not the result of racist individuals acting in racist ways' but is entangled in medical, cultural, historical and social understandings of race and pain. $^{27}$

\section{Ethnicity and pain}

Studies show that immigrants report more experiences of discrimination in healthcare than American-born people of colour. ${ }^{1328-30}$ In the USA, new immigrant populations experience greater barriers to healthcare. ${ }^{31} 32$ Refugees are less likely to seek and use medical resources, often because of cultural, ${ }^{33}$ language, ${ }^{34}$ economic $^{35}$ and trust ${ }^{36}$ barriers. Studies show that race bias may be more pervasive when patients are also immigrants. When the study by Trawalter et al controlled for race, results showed that participants' perceptions of the hardship their patients might have endured accounted for the racial bias in perceptions of others' pain. ${ }^{27}$ This study bears relevance for Somali refugees, who are associated with adversity, struggle and trauma. Somali women, as often visibly Muslim women, are doubly contextualised in narratives of victimhood and oppression: seen as victims of war and exile and of abusive men and oppressive religion. ${ }^{37}$ Somali women may be doubly disadvantaged in pain care, where they signify automatic victims, impervious to physical pain and injured by cultural oppression, not physical affliction.

Pain is a multidimensional experience, which means there are many possible reasons why pain experiences may differ by gender, race or ethnicity. These differences may affect willingness to report pain, ${ }^{67}$ pain assessment ${ }^{101415}$ and pain behaviour. ${ }^{17} 1822$ Studies of the social and cultural meanings that different groups bring to the experience of pain can help facilitate better pain diagnoses, treatment and management. Such studies can also develop deeper understandings of how groups express and handle pain and a fuller understanding of pain. This study addresses the pain experiences, strategies and stories of participants who belong to a population commonly undertreated within medical institutions. This study responds to sociologist Joanna Kempner's observations that much social science research on chronic pain focuses on white women and that such samples of white, middle-class women produce incomplete results. ${ }^{2}$ Intersectional approaches to pain research are necessary to 'reveal $[. .$.$] how racialized institutions shape illness experi-$ ence and medical care' but to address 'how these institutions make some individuals visible, while rendering others invisible' (p. 154). ${ }^{2}$ In a context of unmet needs and clinical impasse of inexplicably debilitated bodies and over-riding public narratives about raced bodies, it is important to pay attention to how individuals express their own pain.

An intersectional approach to chronic pain can both heed under-represented voices about pain and capture the layered institutional barriers confronting patients. This study asks how Somali women understand pain and pain management and how 
Somali women use informal and formal systems of pain management. These questions aim to (1) generate a better understanding of the social and cultural dimensions of chronic pain; (2) map the barriers Somali women experience to accessing care and (3) highlight the strategies and resources that Somali women use to effectively manage and care for chronic pain.

\section{BACKGROUND ON SOMALI MIGRATION AND RESETTLEMENT}

Refugees from Somalia, a country located in the Horn of Africa, have experienced decades of civil war and conflict-induced displacement. ${ }^{3839}$ Beginning in 1978 and escalating in the 1990s, Somalia has been embroiled in clan-based civil war. ${ }^{38}$ Ongoing intraclan conflict has prevented efforts to install a stable government. ${ }^{39}$ Fleeing this warfare, many Somali people migrated to refugee camps in Kenya and Ethiopia. Several counties, including the USA, sponsored refugees and resettled refugees and their families. ${ }^{38}$ The Somali diaspora has continued to grow in the USA as civil war persists in Somalia and US policies facilitate family reunification. ${ }^{38}$ The 2017 US travel ban, however, has stalled family reunification efforts and Somali immigration into the USA.

On arrival in the USA, refugees go through an initial resettlement process. Resettlement agencies place families or individuals in homes, connect them with social services and enrol them in cultural orientation classes. These practices aim to help resettled refugees become quickly self-sufficient. Research on refugee resettlement, however, shows that learning how to navigate life in a new country is a lifelong process. ${ }^{34041}$ Because many resettlement agencies focus on employment and housing, ${ }^{34} 40$ non-emergency health needs are often insufficiently met. ${ }^{40}$ Refugees without immediate health needs have little support in building medical relationships. ${ }^{41}$ Refugees continue to face structural barriers accessing and navigating the healthcare system, including language, literacy, culture and trust. ${ }^{4041}$

A 2005 report by the Minnesota Department of Health found that Somali refugees in Minnesota, where the largest number of Somali refugees live in the USA, are the least served by Minnesota's health and social service systems. ${ }^{31}$ The same study found that Somali refugees who develop chronic conditions suffer higher rates of disease morbidity than white populations. ${ }^{31}$ In response to these identified disparities, many medical and health communication researchers and health professionals are calling for more culturally and linguistically appropriate care. ${ }^{30} 3342$ While this study agrees with calls for more culturally attuned and accessible medical care, this article looks less at how patients benefit or not from medical resources and examines how participants interact with and change medical knowledge and practices in inventive and constrained ways.

\section{METHODS}

This article derives from an ongoing study designed and conducted in partnership with a Somali-serving health centre (centre X) in a Midwestern city. This centre offers culturally attuned health literacy courses to Somali girls and women that focus on topics including: American healthcare basics, preventative health for cervical and breast cancer; sexual health and sexual abuse: what is it and what to do; healthcare: know your rights. In June 2016, health educators began developing a health literacy course on chronic pain, a condition they had noticed among their Somali clients. As Cawo, a health educator, explained to me, 'Women are always coming to learn about how to take care of their families and kids, and then we learn, months
Table 1 Participants

\begin{tabular}{|c|c|c|c|c|}
\hline Participant $^{*}$ & Age & $\begin{array}{l}\text { Years } \\
\text { in the } \\
\text { USA }\end{array}$ & Occupation & $\begin{array}{l}\text { Self-described } \\
\text { diagnosis }\end{array}$ \\
\hline Ashwaq & 38 & 12 & $\begin{array}{l}\text { Charter school } \\
\text { administration }\end{array}$ & Lupus \\
\hline Ayan & 38 & 11 & Public school aide & Lupus \\
\hline Fatumo & 50 & 14 & Unemployed & $\begin{array}{l}\text { Headaches, pain; thyroid } \\
\text { disorder }\end{array}$ \\
\hline Fowsio & 42 & 9 & $\begin{array}{l}\text { Non-profit } \\
\text { administration }\end{array}$ & Autoimmune disease \\
\hline Kadra & 40 & 15 & Store owner & Headaches \\
\hline Ladan & 56 & 14 & Unemployed & Headaches \\
\hline Muna & 39 & 15 & $\begin{array}{l}\text { Non-profit programme } \\
\text { coordinator }\end{array}$ & $\begin{array}{l}\text { Endometriosis and } \\
\text { infertility; post-traumatic } \\
\text { stress disorder }\end{array}$ \\
\hline Nimo & 38 & 22 & Refugee case manager & $\begin{array}{l}\text { Rheumatoid arthritis; } \\
\text { heart disease }\end{array}$ \\
\hline Ruqiyo & 29 & 6 & Unemployed & $\begin{array}{l}\text { Chronic pelvic and back } \\
\text { pain }\end{array}$ \\
\hline Sahra & 41 & 10 & Unemployed & Autoimmune disease \\
\hline Waris & 56 & 16 & Unemployed & Pain and headaches \\
\hline Warsan & 39 & 7 & Unemployed & $\begin{array}{l}\text { Headaches; thyroid } \\
\text { disorder }\end{array}$ \\
\hline Asma & 22 & 20 & $\begin{array}{l}\text { Centre } \mathrm{X} \text { health } \\
\text { educator }\end{array}$ & -- \\
\hline Carwo & 26 & 23 & $\begin{array}{l}\text { Centre } \mathrm{X} \text { health } \\
\text { educator }\end{array}$ & -- \\
\hline Guhaado & 24 & 24 & $\begin{array}{l}\text { Centre } \mathrm{X} \text { health } \\
\text { educator }\end{array}$ & --- \\
\hline
\end{tabular}

*All names used are pseudonyms.

later, that these women are also in need of medical help, but they never will use it themselves unless it is an emergency'.

To develop a curriculum on chronic pain, the centre hosted a series of bimonthly listening sessions with Somali women who identified as having chronic pain. I volunteered at centre $\mathrm{X}$ for 4 months before I began this study, and I was volunteering when the listening session development began. Since I had been studying chronic pain, I provided resources for health educators to distribute to listening session participants. These resources included definitions of chronic pain conditions and useful English terms and information about local clinics. As I provided these resources, we discussed the relative lack of research on Somali women with chronic pain, and we began to envision a research study. When I began this study, my role changed from contributing material for listening session participants to exclusively observing listening sessions.

\section{Participants}

This article draws from in-depth interviews with Somali women who identify as living with chronic pain $(n=12)$, participant observations from chronic pain listening sessions $(n=15)$, two focus group meetings $(n=8$, with overlap in participants who were interviewed and participated in focus groups) and three in-depth interviews with health educators at centre $X(n=3)$ (table 1). To be eligible for an interview, participants had to be at least 18 years of age and either (1) Somali and identifying as living with chronic pain or (2) a health educator at centre X.

This study classifies pain according to the IASP's definition of pain as unpleasant, sensory and associated with real or potential tissue damage. ${ }^{4}$ Participants identify as experiencing physical pain. Although conditions such as depression and post-traumatic 
stress disorder are often inseparable from chronic pain, ${ }^{4} 4344$ this study does not focus on mental or emotional sources of chronic pain. This classification of pain as physical is not meant to suggest Somali women reporting chronic pain are not also living with trauma and psychosomatic pain. ${ }^{5} 4344$ Trauma and its health consequences, however, are outside the bounds of this study. Untangling emotional and physical causes of pain is also outside the bounds of this study; instead, and because many women report to having their chronic pain pre-emptively attributed to mental and emotional causations, this study takes at face value participants' claims to experience chronic pain.

Study participants who are Somali women living with chronic pain ranged from 29 to 56 years. Participants have lived in the USA from 6 to 22 years, with an average time in the USA of 12.58 years.

\section{Data collection}

I partnered with centre $\mathrm{X}$ to recruit participants from chronic pain listening sessions. I observed chronic pain listening sessions and health educators' follow-up meetings. This study also used interviews and focus group interviews. All interviews and focus groups were conducted at centre X or a participant's home. Interview questions were open-ended, semi-structured questions designed to follow aspects of chronic pain participants most wanted to discuss. Original questions for women with chronic pain included: how participants told and recalled their stories of life with chronic pain; what their diagnostic processes entailed; what meanings they made of their medical diagnoses or lack of medical diagnoses; how they practised health and responded to illness; what kinds of healthcare resources they used and what therapies they felt worked; what barriers they faced in accessing and using resources; what expectations they had for pain treatment. Questions for health educators included: what information they thought was important for their clients to know about chronic pain and the American medical system; what actions they hoped their clients would take after attending a course at centre X; what types of support they felt Somali women needed to care for their and their families' health; what barriers they anticipated their clients would face in medical encounters; how they looked after their own health and responded to illness.

Qualitative interviews were an effective method to understand participants' experiences and beliefs around pain and health because the structure of the qualitative interview (openended questions about personal experiences and practices, and questions about how individuals interpret abstract concepts like health) elicited complex narratives. Complex narratives are critical for understanding the depth and nuance of another person's experience as they contextualise knowledge forms that may otherwise be easily dismissed or disproved. These narratives illustrated connections between specific practices and broader approaches to health and illness (p. 15). ${ }^{45}$

\section{Confidentiality and consent}

This study assigns pseudonyms to participants and to the partnering health prevention centre. This decision was made to protect participants' anonymity; since centre $\mathrm{X}$ is a small organisation, revealing its name, the names of its staff or its location would risk rendering participants identifiable. This article has assigned participants aliases-created personas and pseudonyms to represent but anonymise each participant (see table 1).

Consent forms were written in English and interpreted into Somali. Although all participants spoke English, not all participants were confident in their English; therefore, an interpreter was present at all consent meetings and interviews. The interpreter did not interpret whole interviews, but interceded when the participant asked for help or when the interpreter felt that either an interview question or a participant's response was not fully understood. Interpreters were also staff or volunteers at centre X. Interviews were audio recorded if participants agreed, but some participants did not want to be recorded. In these cases, I transcribed interviews non-verbatim. Although many of the quotations included in this article come from interviews I transcribed verbatim, not all quotations are exact. Quotations should be read as close renderings of participants' words, sometimes combining a participant's response and the interpreter's tweaks, rather than an exact replication of participants' voices.

\section{Data analysis}

Grounded Theory was used to analyse interview transcripts and field notes. In Grounded Theory, initial data are often gathered through open-ended interviews and/or open-ended naturalistic observation, as is the case with this study. Data are then coded to develop open codes. Codes are constantly compared with develop categories, properties and patterns from which to build theory. ${ }^{46}$ Grounded Theory is effective to engage understudied phenomena because it allows the researcher to inductively build theory from the data, rather than apply existing frameworks to data (p. 81). ${ }^{46}$ Grounded Theory allowed participants' stories and accounts of their experiences to drive analysis (p. 96). ${ }^{46}$

Memoing was used to track themes emerging from interviews and observations, based on multiple readings of the transcripts and field notes. Memos were organised by theme and then by code. Memoing and coding were repeated over the course of data collection and analysis and codes were refined, solidified and compared across categories and interviews. Because codes were developed from (1) observations of listening sessions, (2) interviews with Somali women who have chronic pain and (3) interviews with health educators, data analysis maintained rigour through triangulation.

Initially, inductive coding produced 44 codes. Codes were compared and resorted into 12 cluster codes, which were then grouped into eight higher-level categories: exile; faith; discrimination and exclusion; natural practices of health and healing; medical expectations; medical disappointments; barriers to access; health literacy. Categories were recoded into four frameworks within which participants described chronic pain: (1) pain as a symptom of exile; (2) pain and the strength to bear pain as issues of faith; (3) medicine as powerful, curative and fluid; (4) medical discrimination and exclusion. Within these frameworks, specific practices of managing pain were identified: medical evaluation, medically prescribed pills and/or treatments; alternative therapies (eg, acupuncture), at-home therapies (eg, nutrition, exercise, spices), faith-based therapies (eg, prayer).

\section{FINDINGS}

Findings from this study show four inter-related frameworks through which participants experienced and made meaning of chronic pain. Participants made decisions about help-seeking and treatment options within these frameworks. Each subsection below describes a framework and provides examples in which participants contextualised chronic pain within this framework or drew from this framework to explain decisions and beliefs.

\section{Framework 1: pain as a symptom of exile}

When participants spoke of their pain, many also spoke of their lost homes in Somalia. In interviews, I would ask participants to 
tell me their stories about chronic pain, beginning wherever they felt their stories started. Many participants began with memories that linked a lost home with bygone health:

I never had pain like this in Somalia. There, I was healthy, I worked hard. My headaches started here. When I was here, there were less Somalis, and I knew no one. And then they (headaches) never went away. (Waris, aged 56 years, 16 years in the USA)

Lupus is when your body attacks itself. For me, that happened when I came here. My husband was still with us, and we were finding a place to live, a school, we didn't know any English. I started getting-pain in my chest, and I couldn't breathe. That was how it started. I did not have a doctor say it was lupus until five years ago, but I know that's when it started. I was healthy in Africa. (Ashwaq, aged 38 years, 11 years in the USA)

It began when I came here in 2012. Back pain ... In Africa, I only had pain in and after childbirth, but nothing like this. (Ruqiyo, aged 29 years, 6 years in the USA)

I first came to Phoenix (Arizona), but we were there for one month, and then the day we moved to Ohio, it was very cold. That was the first day of my headaches, and now they are every day. I remember the cold and the pain, but there is nothing to do. (Kadra, aged 40 years, 15 years in the USA)

Participants experience chronic pain in ongoing relation to memories of Somalia as the site of a healthy body. Many participants traced their experience of chronic pain to the experiences of migration and being strangers in a new land, surrounded by people speaking in an unfamiliar language, filling out paperwork for unknown institutions and settling families into temporary living quarters. Oftentimes, participants' symptoms map onto experiences of rupture and relocation. When I asked Ashwaq if she thought her lupus was caused by migration, she considered,

I don't know, but my doctor does not know either. She says, they don't know what causes lupus or an immune system to attack itself. I think: the new weather, the cold, the new apartment, being inside all the time, just sitting, my husband leaving, missing my mother-do you understand? Just think, if you can never see your mother again, do you see? I think of all of those changes and think, how should my immune system know what is healthy?

Chronic pain is often characterised by the tension of pain's unrelenting reality and medicine's inability to mark, document and explain such pain. Without a clear medical narrative to explain their pain, many participants explained pain as connected to the disruptions and losses that characterise resettlement. Ashwaq acknowledges a respect for and deference to medical expertise ("I don't know, but my doctor does not know either") but then suggests that her pain, which her doctor could not successfully treat, might be medically confounding because of her status as a refugee. Ashwaq articulates both a trust in medical knowledge and a belief that such knowledge does not apply to her. Because she is new to the USA, medical knowledge grown and developed here may not apply to her body. When Ashwaq links her untreatable pain to her status as a refugee, medical uncertainty around chronic pain reaffirms her impression, discussed further in the section 'Framework 4: medical exclusion and discrimination' that she is living in a body and experiencing bodily phenomena unprecedented in American medical study and therefore poorly accounted for in American clinical evaluation and treatment.

\section{Framework 2: pain and the strength to bear pain as issues of faith}

Faith informs the chronic pain experiences of participants and emerged as a central coping strategy in every interview.
Participants often struggled to express the ways that Islam has shaped their lives, values and identities. "It is who I am", Kadra said. Ashwaq explained,

It is hard for Somalis who work and go outside of Somali places because people do not like hijabs, and you have to find your own space to pray, but all of us do. My brother, he memorized all 114 chapters (of the Koran) when he was nine. Now, he doesn't know them all, but he listens to an app when he drives. I do, too, now. It is so important, do you understand? So we find ways.

Like Ashwaq, other participants described Islam both as central to their lives and decisions and as a tradition that unites diaspora Somalis through shared rituals, holidays, clothing and values. While many participants described their pain within experiences of disorientation and isolation, participants also explained pain management in relation to their faith. When asked what they do to manage pain, many participants discussed faith rituals. Nine participants said they prayed, and eight elaborated that they prayed by reading verses of the Koran. "It's the only way I can sleep", Nimo explained. "When I wake up with pain, or with my anxiety", Muna said, "I read verses of the Koran. It's like meditation".

When asked if their faith shaped how they understood their chronic pain or their diagnoses, participants contextualised pain in faith-driven and fatalistic narratives:

I am Muslim. We believe that God knows everything that will happen. (Ladan, aged 56 years, 14 years in the USA)

It (Islam) helps me to know that I have no control. It is for the sake of God that I live with this condition. (Sahra, aged 41 years, 10 years in the USA)

Islam teaches us that humans have no control. But that is a good thing: God gives us strength to handle everything. And, I know, I am very strong. (Ashwaq, aged 39 years, 12 years in the USA)

Islam lets me know that I am strong. I can handle this, or things much worse. (Fowsia, aged 42 years, 9 years in the USA)

Participants draw from religion two explanatory frameworks for chronic pain. The first is a fatalistic one: all events, including pain, are preordained by God, and humans have no power to intervene. This narrative instils participants with a sense of strength: God may be the source of chronic pain, but God also imbues faithful individuals with the strength to handle pain 'or things much worse'. This second framework is one of internal, immanent competency. Faith bolsters participants' belief that they can live with any challenge, including chronic pain, so long as they maintain a close relationship with God.

\section{Framework 3: medicine as powerful, curative and fluid}

Participants who hold fast to religious worldviews, which deny individual efficacy in the face of external control, also actively sought medical resources. When asked what they do when a member of their family is sick, many participants said they seek medical aid:

For my oldest son, he has a heart condition, he has a hole in his heart. If he is sick, I take him to his doctor because of his heart. If he runs too much, gets too excited, he could hurt himself. The wait for his doctor is longer than waiting for the emergency room at the hospital, but it's worth it because his doctor knows [son's name], and he knows if he needs medicine or if he can just go home. The others, if they are not feeling well, they stay home. If something is wrong, they go to the doctor. My daughter broke her wrist in 2014, and I took her to the hospital. (Kadra, aged 40 years, 15 years in the USA) My children go to all their doctors' appointments for school. My son with autism, he goes to doctors or therapists every day. Speech ther- 
apy, behavioral therapy, occupational therapy. Every day, I'm driving him from appointment to appointment. The others are healthy. If something went wrong, I would take them to the doctor. (Ashwaq, aged 39 years, 12 years in the USA)

It ... changes. If they are hurt, a broken bone, I take them to the doctor. If they are ... very sick, I would take them to the doctor. If they are just ... not well, they rest. (Warsan, aged 39 years, 7 years in the USA)

Participants' experiences of health, illness and caregiving in the USA are enmeshed in medical structures and relationships. Yet, while many participants seek regular medical aid for their children, few seek consistent medical care for their chronic pain. When asked if they also sought regular medical aid for their chronic conditions, many participants replied that they sought care if reactions were severe. When I asked Ashwaq about when she sought medical care for herself, she responded:

I did not go to work one day because I felt sick, and the next day I went back, and I just did not feel well. I had a very bad headache, and I had lots of pain. I had chest pains. So my friend took me to the doctor, and they said I had pneumonia, and they gave my antibiotics. Then I went home. Then I went to work, and I still felt very bad. I had chest pains, and then I fainted. Then, I was taken to the hospital, and I had three seizures. This was in 2010. I had them because of a high fever, and so they had to figure out what was wrong. They said I had an infected gallbladder, and they removed my gallbladder. Then, I was fine.

\section{Nimo similarly recalled one instance of seeking medical care:}

I had a very bad heart problem. It wasn't a heart attack, but I thought I was having a heart attack. My friend took me to the hospital, and I had to stay in the hospital for a month. It was awful. The lights never go off, and the nurses are always working. If I fell asleep, one would suddenly be picking up my arm, poking me, checking something. I would say, What are you doing? And they would say, oh, oh, it's ok, don't worry, just checking! And I would say, Just let me know. Or, just wait until I'm awake. It makes you feel like you're not a person, or like you are a machine they are checking. But I got better, and then I went home, and now the pain is more-fine. Sometimes, my kids say, remember when you were in the hospital? My brother had to take in all the kids, with his kids. I hope to never go back.

Nimo and Ashwaq sought medical care when they could no longer function and when friends ferried them to hospitals. Both recall hospitalisation as grim and dehumanising but necessary and ultimately curative. The stories that circulate among participants about medical care characterise medicine as a powerful but dehumanising place, one best avoided unless your body is in critical condition. Yet, when it comes to their children, participants were more likely to see medical care as beneficial. Ashwaq, who has a son with autism, explained that when she secured a diagnosis of autism for her son, she could access a fleet of resources, including speech, behavioural and occupational therapists and waivers for devices like a home alarm system.

For people who live with chronic pain, however, medicine offers a limited and slow-moving cache of resources. Ten participants visited doctors until they either received a diagnosis or grew tired of being told that there was no physical explanation for their pain. These participants reported frustration that, once they gained access to health insurance and a doctor, they did not also gain access to a diagnosis and a cure:

I know that doctors could fix it. They could take images of my legs or hips where the pain is. They can do tests. But they don't do that, but I know that they could. (Ruqiyo, aged 29 years, 6 years in the USA)
It took a very long time to learn what was wrong with me. I wasn't very worried because I was so worried about my son, do you understand? But then, a doctor said, you have lupus. I have lupus. So I have joint pain, headaches every day. I had a patch, a big black patch on my head, and they took skin and said it was lupus. I was so thankful it wasn't ... you know, cancer. I take painkillers, Naproxen, every day, and anti inflammatories. But it never goes away, and I don't go to the doctor much, anymore. (Ashwaq, aged 39 years, 12 years in the USA) After many years, I was diagnosed with rheumatoid arthritis. It's an autoimmune disease. They had medications, one was an injection, but they said nothing would fix it, it was all about management. They said me to a new doctor: pain management doctor. It had already taken years to name what was wrong, so I didn't want pills or injections that might not work. So I stopped going. (Nimo, aged 38 years, 22 years in the USA)

No one knows what is wrong with me. They say, eat, exercise, drink lots of water. And I say, if I have time to myself, am I going to walk? No! I'm going to rest. (Kadra, aged 40 years, 15 years in the USA)

Medical labels for pain offered the initial promise of a medical cure, but when that did not arrive, participants often turned away from medicine. The diagnoses that made a difference to participants were diagnoses that unlocked resources, such as Ashwaq's son's autism diagnosis. Ashwaq's and Nimo's stories of their hospital stays illustrate the detachment with which participants often remembered their medical encounters. These hospital stays were bouts of managed illness that happened to them, and that are remembered as disconnected, bracketed times of their life, periods they hope never to relive.

Health educators at centre $\mathrm{X}$ recognised their clients' tendency to seek medical resources only in emergencies and to expect immediate results; health educators identified a primary job responsibility as educating clients that medical results are not always immediate:

One of our main goals is to teach people about preventative resources. No one goes to the doctor if they are well in Somalia, but that's what they need to do here. We say, go when you're well, find your doctor, start a relationship. Then, when things are bad, you have a doctor who knows you. That strategy works because Somalis really want relationships with their doctors. (Asma, aged 22 years, 20 years in the USA)

Our biggest job is to teach preventative medicine. Somali women die from cervical cancer at really high rates. So we tell women that they have to get tested, or else they'll get this, and we show them pictures of really cancerous cervices. Because the thing is, people want to go to the doctor and leave with something, but we try and say, no, a lot of times, you just make sure things are normal. (Guhaado, aged 24 years, 24 years in the USA)

Centre $\mathrm{X}$ health educators emphasised preventative medicine and tempered expectations. Participants in the chronic pain listening session, however, explained that after learning that doctors could manage but not cure their pain, they preferred to manage pain through domestic, homeopathic or faith-based methods of self-care. Nimo and Waris said that they prayed with their prayer beads. Nimo elaborated that, "When I feel anything coming on at work, a headache, a flare, that's the sudden joint pain, I calm myself by counting my beads under the table. It's more like meditation than praying then, but no one notices".

Other participants used, in addition to prayer, alternative or integrative healing methods. Four participants regularly used acupuncture, and two said that if they had more time and money, they would use acupuncture. Ayan described her experience with acupuncture: "I see an Asian man (describes location), and I feel better when I leave. The first time, I felt much better, and now a little better. My friends go to him, too. His appointments are not 
rushed, and it is a time to rest". Muna said that she attends meditation class that was 'half Somali meditation and half Western meditation, but it's run by a Somali woman'. Two participants said that they use massage. Participants sought medical aid for a diagnosis and a cure, and when medicine could not cure them, they turned elsewhere for care. Participants' accounts of medical treatment were told as isolated experience, while participants' experiences of alternative, at-home, and faith-based therapies were woven into their accounts of daily life and bore a sense of narrative continuity. Participants did not discuss these practices of caregiving as opposed to one another but enacted different modalities of health under one, fluid framework of help-seeking in a foreign land.

\section{Framework 4: medical exclusion and discrimination}

When participants spoke about their experiences of chronic pain within their local and faith communities or within alternative medical settings, race and ethnicity did not emerge as salient categories. However, when discussing their medical interactions, participants noted the ways that they felt markers of gender, ethnicity and race, taken together, influenced their access to and treatment within medical institutions. Participants described medicine as an institution less accessible to them because of their skin colour, clothing, accents or insurance. Many participants felt they received the scraps of medical care:

I am unsure about the pills. The thyroid pills have helped me. But I have MA (Medical Assistance health insurance), so I know that many doctors give patients with MA the not as good pills. (Warsan, aged 39 years, 7 years in the USA)

Doctors see: woman, hijab, bad English, MA, and they don't do as much. They think ... I don't know. We're poor, don't understand anything, I don't know. (Ruqiyo, aged 29 years, 6 years in the USA) My doctor asks about my home, about my past, coming here, and that takes up most of the appointment. I don't want to talk, to have to tell him these things, I want him to tell me what to do. (Ruqiyo, aged 29 years, 6 years in the USA)

They see a hijab and they think, won't understand. They also think: abused, oppressed. They think my problem is my husband, or my religion, and they won't treat my head. (Kadra, aged 40 years, 15 years in the USA)

Kadra and Ruqiyo were not alone in expressing frustration that medical professionals suggested, directly or indirectly, that their pain may not be wholly physical and could be caused by psychological, psychosomatic or psychogenetic factors. Much research supports that trauma can cause health problems and that cultural stigma surrounding mental illness deters many Somali patients from seeking mental healthcare ${ }^{44}$. Kadra's and Ruqiyo's complaints, however, should not be automatically attributed to this explanatory framework. Participants did not demonstrate an aversion to thinking of pain as multifactorial; many participants explained their pain as connected to experiences of exile, migration, resettlement, discrimination, isolation and resource-scarcity. Participants frequently reflected on social and emotional dimensions of pain, but many expressed an aversion to having their medical doctors probe social and emotional dimensions of their pain.

Writer Meghan O'Rourke argues that the medical response to a woman in pain is too often 'Why is something wrong with her?' and rarely 'What is wrong with her?' ${ }^{147}$ The former question elicits a life story while the latter necessitates a biomedical examination. Kadra and Ruquiyo preferred a medical professional adept at examining the body's physical state but not inclined to probe its emotional traumas. Kadra and Ruqiyo described finding emotional support elsewhere in their lives, including in their communities, families, mosques and health educators. These findings show that participants recognise the non-physical complexities of chronic pain, but that they resist medical professionals' involvement in the non-physical dimensions of pain management, especially when such involvement assumes experiences of trauma based on their ethnicity.

Other participants identified language or culture barriers to medical care:

I arrive with so much to say. I've followed the 'flares,' they call it, the 'brain fog.' All of it, but it is so hard to explain, so I don't know how to tell my doctor. (Fowsia, aged 42 years, 9 years in the USA)

Once, I brought all my kids at once to the doctor because it was too hard with all the appointments and shots, and once I took one kid for another kid's appointment, and they were angry. So, I brought them all, and they were very angry. I feel, I worried, is that why my son is not getting diagnosed for his ... he has a developmental disability. Now, for myself, I worry, too. Am I annoying? Am I doing something wrong? (Ayan, aged 38 years, 11 years in the USA)

They have interpreters, but interpreters are not good. But if I bring my daughter, she doesn't know how to translate the words for me, and it's not a good appointment. (Ladan, aged 56 years, 14 years in the USA)

These stories and suspicions about medical providers, regardless of their veracity, show that participants experience racial, classed, gendered and ethnic discrimination healthcare. Participants worry that they receive lower quality medical interventions because of their race and ethnicity. Participants worry their physicians assume they are uneducated and overburdened and withhold accurate information. Participants express distrust in medical interpreters to accurately communicate information. For participants, medical care offers curative resources and many tests. To make claims to medicine about their bodily pain, participants seek ways to make their pain convincing (but not 'annoying' lest they make a practitioner 'mad'), medically legible and accurate. Many participants did not feel up to the rhetorical labour of communicating their pain effectively and truthfully to their English-speaking providers. These participants adopted more accessible forms of care, including complementary medicine, faith rituals and at-home, homeopathic treatments.

\section{DISCUSSION}

Given that 15 women were interviewed and observed for this study, these findings are not generalisable. However, these findings confirm past research in several areas and delineate future research directions. This study aligns with research that shows that Somali refugees experience medical care as inaccessible and discriminatory. ${ }^{7} 3648$ This study affirms the need for culturally sensitive care to respond to entrenched health disparities. ${ }^{42}$

This study contributes four frameworks through which participants experience chronic pain: (1) pain as a symptom of exile, (2) pain and the strength to bear pain as issues of faith, (3) medicine as a curative and powerful institution and (4) medicine as a racist and classist institution that heals only those who know how to navigate its intricacies. This study addresses relationships between somatic changes and social changes through a discussion of how participants move within and bring into relationship these four frameworks. These frameworks bring into focus the social and cultural contexts in which participants experience pain, the expectations, hopes and anxieties that participants bring into medical encounters, and the strategies that participants use to manage chronic pain. These frameworks show how participants mediate between layers and modes of health 
knowledge to make decisions about their health and healthcare. Learning how patients navigate divides between biomedicine and other modes of medicine, healing and caregiving is critical to understand the diversity of patient experience and the experiences of underserved patients.

\section{Chronic pain and lived context}

For participants, stories about chronic pain often start with a memory of home. Participants' tendency to trace pain back to their first memories of resettlement align with the findings of Svenberg et al from an interview-based study about health and illness beliefs among Somali women living in Sweden that 'one major and essential theme that was always present and permeated each subject discussed: a life in exile' (p. 283) ${ }^{48}$ and that pain was expressed as 'a companion in exile, prejudice and discrimination, family' (p. 285). ${ }^{48}$ For participants, talking about home is a way of talking about many things at once: the experience of a lost home and the ongoing experiences of trauma and disorientation in resettlement; the experience of medicine as an institution that feels helpful and inaccessible; the expectation of medicine as curative dissolved through the experience of chronic pain. Although all participants recognised pain as a physical reality, participants' stories about pain did not abstract symptoms from the lived experiences of exile, migration and resettlement.

\section{Flexible fatalism}

Participants contextualised pain in memories of an irretrievable home and in faith. Participants explained that their faith reminded them that humans do not have the power to understand, change or heal pain. Such a fatalistic worldview-one that attributes control to an external locus-does not map onto a medical understanding of pain and illness. While it may seem logical that a fatalistic worldview would deter individuals from seeking medical aid or partaking in preventative healthcare, ${ }^{26-28}$ such is not the case for participants. When I asked participants how they resolved their religious beliefs that healing was solely the work of God with their decisions to seek medical aid, participants rarely acknowledged any tension:

(Interviewer): So, it seems to me like it must be strange. You explained how in Somalia, if something was wrong, people would just go to the mosque for healing. And here, everyone goes to the doctor. Is it weird, going to the doctor for healing?

Sahra: No, no I go to the doctor and go to the mosque.

(Interviewer): I've been thinking about this a lot in interviewing people. It seems like, for anyone with a strong faith, Islam or otherwise, there's this sense that the true healing power is God's.

Nimo: Yes.

(Interviewer): So, is it hard to go to the doctor for healing? When it should be God doing the healing?

Nimo: No, I don't think so.

The problem that I was sensing was not a problem for participants, who did not experience as oppositional biomedical and religious approaches to the body.

Past studies have identified fatalism as a possible explanation for otherwise seemingly self-harming health behaviours (eg, refusing preventative cancer screenings). ${ }^{49} 50$ As per the ethnographic study of Appalachian women's health by Drew and Schoenberg, decisions about preventative cancer treatment reject this categorisation of fatalism and modernity and argue that people ascribe to fatalistic health beliefs for 'numerous and complex factors' including lack of health insurance, legacies of self-reliance, poverty, fear concerning invasive or risky medical procedures and concerns about privacy or suboptimal medical treatment (p. 172).$^{50}$ Participants in the study by Drew and Schoenberg feared getting a pap test because, if the result were positive, they could not afford medical care (p. 172). ${ }^{50}$ In such a bind, ascribing to fatalistic ideas about illness may make more sense than taking test without the means to seek treatment in the case of a positive result.

This study argues that fatalism may be a strategic and, at times, wholly logical way of negotiating a medical system that one cannot access because of financial, logistical, language and educational barriers. A fatalistic, religious worldview does not exist only at the exclusion of a medically informed understanding of health disease. Participants extolled medicine and pursued its interventions and, if they encountered barriers to access or cure, participants turned to faith-based understandings of illness for comfort and a kind of healing.

Participants enacted biomedical and faith-based approaches to healing, illness and care, as different yet mutually enforcing and logically coexisting. Some participants explained using medical interventions to attend to their children's health while attributing their own chronic pain to divine and impenetrable causes. As framework 3 shows, participants ascribe to religious beliefs about how illness and pain work and actively seek medical and alternative medical treatments. Medical, integrative, homeopathic and faith-based approaches to and understandings of illness and disease peaceably coexist.

\section{Emerging medical narratives}

Sociologist Arthur Frank has argued that many ailing Americans go to the doctor with the expectation of being healed and returning to their momentarily inaccessible health bodies. ${ }^{51}$ This expectation comes from a dominant medical narrative, the restitution narrative, which Frank summarises: "Yesterday I was healthy, today I'm sick, tomorrow I'll be healthy again" (p. 77). ${ }^{51}$ Frank argues that when chronic illness renders the restitution narrative impossible-when a person finds herself sick and the doctor cannot provide a diagnosis, treatment, or cure-then this person is often left bereft of identity and narrative predictability. This patient must begin shaping a new narrative to orient her decisions and supply meaning to her experiences (p. 79)..$^{51}$

The restitution narrative also shapes the experiences of participants in this study, who, when they accessed medical examination for their pain, trusted that diagnosis and treatment would follow. Yet, when their pain proved chronic and incurable, participants were not left unmoored, without any familiar narrative to imbue their experiences with meaning and predictability. Rather, participants mapped their experiences of medical disappointment along two, ready narratives. The first is a fatalistic narrative: one that assures the protagonist that her life is prearranged, and that if she focuses on her faith, she will find strength. This narrative is not antimedical or undereducated; rather, it serves as a useful framework that allows patients to continue to use medicine but to draw from other, more reliable resources (eg, faith and faith communities) when medical treatment disappoints. Second, participants turn to a ready explanation for medicine's failings: medicine is racist and classist. Even when doctors failed to name and cure participants' pain, participants still felt that medicine held, or hoarded, the answers to their problems, but that they lacked the resources and know-how to unlock that knowledge. 


\section{Medical relationships, expectations and adaptions}

This narrative expectation-that Somali women must navigate a discriminatory medical system-shapes participants' medical experiences. Claiming chronic pain before medical professionals requires Somali women to do complicated rhetorical labour. Participants, on their own or in collaboration with interpreters and/or accompanying family member and friends, must accurately and convincingly convey the nature and severity of their pain to physicians. Such rhetorical work coupled with the expectation that medical practitioners can and should cure pain dissuaded participants from seeking medical care. All participants described the US medical system as 'complicated', 'exhausting' or 'hard to understand'.

Expressing chronic pain is difficult for anyone, and this labour is intensified for those who communicate across language and literacy barriers. Especially when it comes to the complexity of expressing pain in different, therapeutic and medical settings, grounded relationships are important to Somali participants' medical experiences. Even though alternative treatments like acupuncture did not cure the chronic pain experienced by participants, participants continued to use acupuncture because they could attend acupuncture regularly and develop relationships with their practitioners. The same can be said of the health literacy courses at centre X: these courses did not teach participants how to access the kind of medical help that would diagnose and cure their pain, but they did provide a reliable space for participants to talk about pain, medicine, discrimination and life. This study emphasises the importance of sustained relationships in caring for chronic, multifactorial pain.

This study shows that participants benefit from emotional and material support from informal networks, including family, friend and community groups, and from faith-based networks. Participants also experienced benefits from medical care, especially during medical emergencies. Yet, no participants involved medical relationships and treatments as part of their daily routines of pain management. Participants did not feel that they had easy access to medical institutions. Participants described medical care as structured by racial, ethnic, gendered and classbased discrimination. Yet, experience of discrimination did not dilute participants' belief in the power of medical knowledge to label and treat disease and injury. Participants continued to seek medical aid but were interested in medical support insofar as medicine could improve or cure a problem. This study shows that participants appreciated the nuances of the multicausal nature of chronic pain, but often came to medical practitioners for an exclusively physical evaluation. Participants themselves inventively coordinated diverse forms of care-medical care, alternative/integrative care, at-home care, faith-based care-to manage the emotional, physical and logistical dimensions of chronic pain. Participants were not averse to collaborative and holistic approaches to pain management, but for long-term health management relationships, participants turned to faithbased healing or alternative practitioners.

This study shows that participants valued sustained relationships, but they did not want to foster these relationships with medical professionals. This study emphasises that more research into the work of alternative medical practitioners and health educators can better understand the pain-coping strategies of underserved groups. For medicine to be accessible to and inclusive of non-native, limited English-speaking patients, consideration must go beyond including translators and promoting health literacy. An over-focus on translation or health literacy could obscure the manifold, strategic and adaptive ways that participants have joined together different forms of literacy and medical caregiving to attend to their health within a structurally inequitable healthcare system. This study points to a need for research that seeks to understand, empower and broaden the work undertaken by community health educators, or 'the in-between people', as they have been recognised in Alaskan Native communities (p. 167), ${ }^{52}$ particularly for immigrant, refugee and multilingual populations. Patients often learn about and navigate healthcare with community health workers, a less studied and less supported part of the American healthcare system. Community health workers facilitate important connections to the healthcare system, and can be trusted sponsors for refugee families access to healthcare. More research should look at the healthcare, relationship-building and caregiving work that community health educators undertake, as this work can be critical for populations under-represented in and underserved by medicine.

Acknowledgements The author would like to thank all the Somali women who opened up their lives and homes to the author and shared their stories. The author would like to thank the community health educators who shared their knowledge and allowed the author into their professional lives. The author would also like to thank the two anonymous reviewers for the journal-provided insightful feedback that improved this article.

Funding This project was funded by the Social Science Research Council Dissertation Proposal Development Grant.

Competing interests None declared.

Patient consent Obtained. Participants have been given aliases-created personas and pseudonyms throughout this paper.

Ethics approval This study has been approved by the Institutional Review Board of the University of Minnesota.

Provenance and peer review Not commissioned; externally peer reviewed. Data sharing statement Unpublished data from this study are not available.

(C) Article author(s) (or their employer(s) unless otherwise stated in the text of the article) 2018. All rights reserved. No commercial use is permitted unless otherwise expressly granted.

\section{REFERENCES}

1 National Centre for Complementary and Integrative Health. Pain prevalence and severity in adults [Internet]. Bethesda, MD: National Institute of Health. 2015 https://nccih.nih.gov/research/statistics/NHIS/2012/pain/severity (cited 15 Feb 2018).

2 Kempner J. Invisible people with invisible pain: a commentary on "even my sister says i'm acting like a crazy to get a check": race, gender, and moral boundary-work in women's claims of disabling chronic pain. Soc Sci Med 2017;189:152-4.

3 Pizzo PA, Clark NM. Alleviating suffering 101--pain relief in the United States. N Engl J Med 2012;366:197-9.

4 IASP Taxonomy. International association for the study of pain. $2017 \mathrm{https}$ ://www. iasp-pain.org/Taxonomy (cited 15 Feb 2018).

5 Turk DC, Okifuji A. Perception of traumatic onset, compensation status, and physical findings: impact on pain severity, emotional distress, and disability in chronic pain patients. J Behav Med 1996;19:435-53.

6 Tilikainen M. Suffering and symptoms: aspects of everyday life of Somali refugee women. Lilius MS, eds. Variations of the theme of somaliness. Turku: Centre for Continuing Education of Abo Akedemi University, 2001:309-17.

7 Finnström B, Söderhamn O. Conceptions of pain among Somali women. J Adv Nurs 2006:54:418-25

8 Korschel M. English - Somali, Somali - English Dictionary. New Delhi: Star Publications PVT, 1995.

9 Rollman GB, Lautenbacher S. Sex differences in musculoskeletal pain. Clin J Pain 2001;17:20-4.

10 Unruh AM. Gender variations in clinical pain experience. Pain 1996;65:123-67.

11 Fillingim RB, King CD, Ribeiro-Dasilva MC, et al. Sex, gender, and pain: a review of recent clinical and experimental findings. J Pain 2009;10:447-85.

12 Chen EH, Shofer FS, Dean AJ, et al. Gender disparity in analgesic treatment of emergency department patients with acute abdominal pain. Acad Emerg Med 2008; 15:414-8.

13 Chang AM, Mumma B, Sease KL, et al. Gender bias in cardiovascular testing persists after adjustment for presenting characteristics and cardiac risk. Acad Emerg Med 2007;14:599-605. 
14 Hoffmann DE, Tarzian AJ. The girl who cried pain: a bias against women in the treatment of pain. J Law Med Ethics 2001;29:13-27.

15 Calderone $\mathrm{KL}$. The influence of gender on the frequency of pain and sedative medication administered to postoperative patients. Sex Roles 1990;23:713-25.

16 Tsang A, Von Korff M, Lee S, et al. Common chronic pain conditions in developed and developing countries: gender and age differences and comorbidity with depressionanxiety disorders. J Pain 2008;9:883-91.

17 Nayak S, Shiflett SC, Eshun S, et al. Culture and gender effects in pain beliefs and the prediction of pain tolerance. Cross-Cultural Research 2000;34:135-51.

18 Lichtman JH, Leifheit-Limson EC, Watanabe E, et al. Symptom recognition and healthcare experiences of young women with acute myocardial infarction. Circ Cardiovasc Qual Outcomes 2015;8:S31-8.

19 Edwards CL, Fillingim RB, Keefe F. Race, ethnicity and pain. Pain 2001;94:133-7.

20 Roberts D. Fatal invention: how science, politics, and big business re-create race in the twenty-first Century. New York: The New Press, 2012.

21 Green CR, Anderson KO, Baker TA, et al. The unequal burden of pain: confronting racial and ethnic disparities in pain. Pain Med 2003:4:277-94.

22 Todd KH, Deaton C, D'Adamo AP, et al. Ethnicity and analgesic practice. Ann Emerg Med 2000:35:11-16.

23 Hoffman KM, Trawalter S, Axt JR, et al. Racial bias in pain assessment and treatment recommendations, and false beliefs about biological differences between blacks and whites. Proc Natl Acad Sci U S A 2016;113:4296-301.

24 Washington HA. Medical apartheid: the dark history of medical experimentation on black americans from colonial times to the present. New York: Doubleday, 2006.

25 Holloway KFC. Private bodies, public texts: race, gender, and a cultural bioethics. Durham: Duke University Press, 2011.

26 Anderson KO, Green CR, Payne R. Racial and ethnic disparities in pain: causes and consequences of unequal care. J Pain 2009;10:1187-204.

27 Trawalter S, Hoffman KM, Waytz A. Racial bias in perceptions of others' pain. PLoS One 2012;7:e48546.

28 Bonham VL. Race, ethnicity, and pain treatment: striving to understand the causes and solutions to the disparities in pain treatment. J Law Med Ethics 2001;29:52-68.

29 Lauderdale DS, Wen M, Jacobs EA, et al. Immigrant perceptions of discrimination in health care. Med Care 2006;44:914-20.

30 Betancourt JR, Green AR, Carrillo JE, et al. Defining cultural competence: a practical framework for addressing racial/ethnic disparities in health and health care. Public Health Rep 2003:118:293-302.

31 Minnesota Department of Health. Immigrant health: a call to action. Minneapolis, MN: Minnesota Department of Health. 2005 http://www.health.state.mn.us/divs/idepc/ refugee/topics/immhealthrpt.pdf

32 Healthy People 2020. Disparities. Washington, DC: U.S. Department of Health and Human Services. 2010 https://www.healthypeople.gov/2020/about/foundationhealth-measures/Disparities

33 Annamalai A. Culturally appropriate care. Annamalia A, eds. Refugee health care: a practical medical guide. New York: Springer Science and Business, 2014
34 Beiser M, Hou F. Language acquisition, unemployment and depressive disorder among Southeast Asian refugees: a 10-year study. Soc Sci Med 2001;53:1321-34.

35 Edberg M, Cleary S, Vyas A. A trajectory model for understanding and assessing health disparities in immigrant/refugee communities. J Immigr Minor Health 2011;13:576-84.

36 Pavlish CL, Noor S, Brandt J. Somali immigrant women and the American health care system: discordant beliefs, divergent expectations, and silent worries. Soc Sci Med 2010;71:353-61.

37 Mahmood S. Politics of piety: the islamic revival and the feminist subject. Princeton University Press: Princeton, 2010

38 Abdi CW. Elusive Jannah: the somali diaspora and a borderless Muslim identity. Minneapolis: University of Minnesota Press, 2015.

39 Griffiths D, Sigona N, Zetter R. Refugee community organizations and dispersal. Bristol: Policy Press, 2005.

40 Beiser M. Resettling refugees and safeguarding their mental health: lessons learned from the Canadian Refugee Resettlement Project. Transcult Psychiatry 2009:46:539-83.

41 Hou F, Beiser M. Learning the language of a new country: a ten-year study of english acquisition by South-East Asian Refugees in Canada. Int Migr 2006:44:135-65.

42 Ezenkwele UA, Roodsari GS. Cultural competencies in emergency medicine: caring for Muslim-American patients from the Middle East. J Emerg Med 2013;45:168-74.

43 Boothby N. Trauma and violence among refugee children. In: Marsella AJ, Bornemann T, Ekblad S, Orley J, eds. Amidst peril and pain: the mental health and well-being of the world's refugees. Washington, DC: American Psyschological Association, 1994:239-59.

44 Kroll J. Posttraumatic symptoms and the complexity of responses to trauma. JAMA 2003;290:667-70

$45 \mathrm{Mol}$ A. The body multiple: ontology in medical practice. Durham: Duke University Press, 2002.

46 Charmaz K. Constructing grounded theory. London: Sage, 2014.

47 O'Rourke M. The mysteries of chronic illness. Cambridge, MA: Radcliffe Institute for Advanced Study at Harvard University, 2014.

48 Svenberg K, Mattsson B, Skott C. 'A person of two countries'. Life and health in exile: Somali refugees in Sweden. Anthropol Med 2009;16:279-91.

49 Gregg J, Curry RH. Explanatory models for cancer among African-American women at two Atlanta neighborhood health centers: the implications for a cancer screening program. Soc Sci Med 1994;39:519-26.

50 Drew EM, Schoenberg NE. Deconstructing fatalism: ethnographic perspectives on women's decision making about cancer prevention and treatment. Med Anthropol $Q$ 2011;25:164-82.

51 Frank A. The wounded story teller: body, illness, and ethics. Chicago: University of Chicago Press, 1994

52 Satterfield D, Burd C, Valdez L, et al. The "in-between people": participation of community health representatives in diabetes prevention and care in American Indian and Alaska Native communities. Health Promot Pract 2002;2:166-75. 